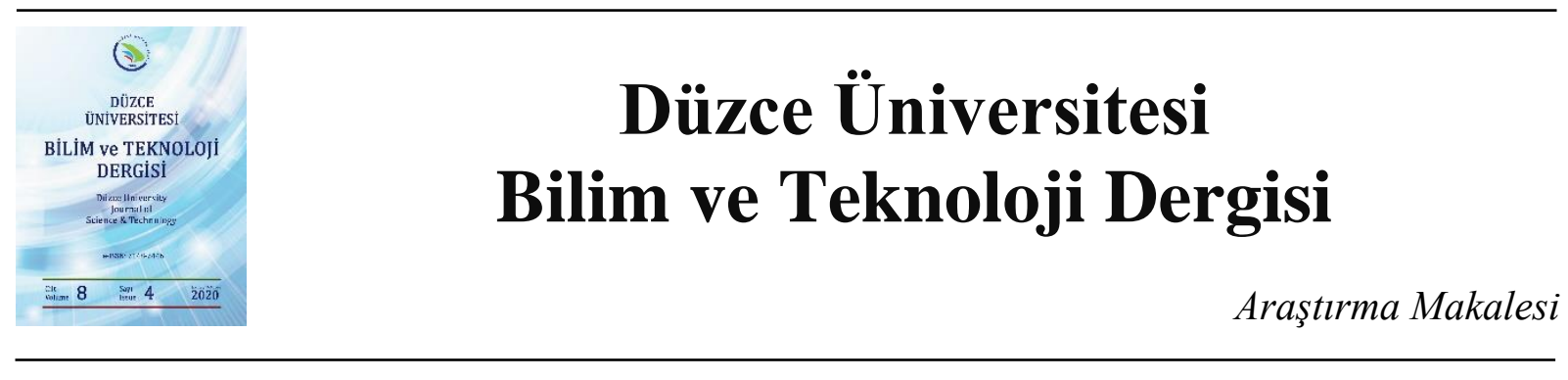

\title{
Belirli Güç Kalitesi Problemlerinin Nesnelerin İnterneti Teknolojileri ile Tespiti ve Bulut Tabanlı Sunuculara Entegrasyonu
}

\author{
Fatih ÇETIN ${ }^{\mathrm{a}, *}$, (i) Nuran YÖRÜKEREN ${ }^{\mathrm{b}}$ \\ ${ }^{a}$ Elektrik Mühendisliği Bölümü, Mühendislik Fakültesi, Kocaeli Üniversitesi, Kocaeli, TÜRKIYYE \\ ${ }^{b}$ Elektrik Mühendisliği Bölümü, Mühendislik Fakültesi, Kocaeli Üniversitesi, Kocaeli, TÜRKIYYE \\ * Sorumlu yazarın e-posta adresi: 175102004@kocaeli.edu.tr
}

DOI : 10.29130/dubited.689757

\begin{abstract}
ÖZET
Elektriğin üretim, iletim, dağıtım ve son kullanıcı alanında kullanımında güç kalitesi problemleri sistem performansını, ekipman ömrünü ve buna bağlı olarak enerjinin verimli kullanımını olumsuz yönde etkiler. Güç kalitesi problemlerini giderebilmek için öncelikle bu problemleri tespit etmek ve kayıt altına almak gereklidir. Araştırmanın amacı güç kalitesi problemlerinin en ekonomik şekilde tespit edilmesi ve büyük veri analizine uygun formatta depolanarak birçok iyileştirme çalışmasına hizmet etmesidir. Araştırma kapsamda belirli güç kalitesi problemlerinin tespitinde nesnelerin interneti altyapısını kullanarak problemlerin tespit edilmesi ve buluttaki sunucularda kayıt altına alınması işlemi gerçekleştirilmiştir. Bu çalışmada belirli güç kalitesi problemlerini tespit eden algoritma geliştirilmiştir. Tasarlanan algoritma ve yeni sistem ekipmanları ile işletmede bulunan geleneksel sistem ekipmanlarından daha düşük yatırım maliyeti ile belirli güç kalitesi problemleri tespit edilebilmektedir. Bu çalışma bir tesiste belirli ölçüm noktasında yeni tasarlanan sistemin kurulması ve 48 saatlik ölçüm alınması ile test edilmiştir. Test verileri incelendiğinde tasarlanan algoritma ve sistemin işletmede oluşan güç kalitesi parametrelerini ve problemlerini tespit ederek buluttaki sunuculara gönderdiği tespit edilmiştir. Yapılan maliyet analizi ile mevcut sisteme göre yeni tasarlanan sistemin \%47,15 oranında daha az yatırım maliyeti ile yapılabildiği görülmüştür. Bu tip çalışmaların artırılması ve devamında büyük veri, yapay zeka uygulamaları ile daha derin analizler gerçekleştirilmesi sağlanabilmektedir. Böylece elektrik sistemlerinin performansı daha düşük yatırım maliyetleri ile optimize edilerek enerji verimliliği artırılabilmektedir.
\end{abstract}

Anahtar Kelimeler: Güç Kalitesi, Nesnelerin İterneti (IoT), Bulut (Cloud) Teknolojisi, Enerji Verimliliği, Uzun Süreli RMS Değişimleri, Gerilim-Akım Dengesizliği, Maliyet Optimizasyonu

\section{Detection of Specific Power Quality Problems with Using Internet of Things Technologies (IoT) and Integration to the Cloud Based Servers}

\begin{abstract}
Power quality problems in production, distribution and end-user areas of the electricity affects negatively to the system performance, equipment lifetime and due to that usage of the energy consumption. To be able to eliminate the specific power quality problems, firstly these problems must be detected and recorded. The aim of this study is detecting the specific power quality problems economically and serving the improvement activities by collecting the specific power quality problems in accordance with the big data analysis. Within the scope of this study, specific power quality problems are detected by using the Internet of Things infrastructure and recorded at the servers in the cloud. In this study, an algorithm which detects the specific power quality problems is developed. With the developed algorithm and new system equipment, specific power quality problems can be detected with
\end{abstract}


lower investment costs than traditional system equipment which is in the plant. This study is tested with the implementation of the developed system in the MCC- 2 board of the plant and with taking 48 hours of measurement. When the test data were examined, it is observed that the developed algorithm and system detected the specific power quality parameters and problems in the plant and sent them to the servers in the cloud. With the cost analysis, it was confirmed that the newly developed system can be built with $47.15 \%$ less investment cost than the existing system. It is possible to perform in-depth analysis with increasing these kinds of studies and afterwards big data, artificial intelligence applications. Thus, energy efficiency can be increased by optimizing the performance of the electrical systems with lower investment costs.

Keywords: Power Quality, Internet of Things (IoT), Cloud Technology, Energy Efficiency, Long duration RMS Variations, Voltage-Current Imbalance, Cost Optimization

\section{GIRISS}

Teknolojik gelişmeler her alanda değişime neden olurken elektrik güç sistemlerine bağlı yük karakteristiklerini de değiştirmektedir. Bu yük karakteristikleri incelendiğinde yarı iletken teknolojisine sahip güç elektroniği cihazları, doğrusal olmayan yükler, değişken hız sürücüleri vb. ekipmanlar doğası gereği güç sistemlerinde bozucu etkilere sebebiyet verirler [1]. Bu etkiler gerilim, akım veya frekans sapmalarından ortaya çıkan ekipmanların arızalanmasına veya düzgün çalışmamasına neden olan güç problemleridir [2]. Güç problemlerinin bütünü ise güç kalitesi problemleri olarak tanımlanabilir. Buna bağlı olarak yaygın olarak karşılaşılan güç kalitesi olayları: (1) Geçici olaylar (Transients) (2) Kısa süreli RMS değişimleri (Short duration RMS variations) (3) Uzun süreli RMS değişimleri (Long duration RMS variations) (4) Dengesizlik (Imbalance) (5) Dalga şekli bozuklukları (Waveform distortion) (6) Gerilim dalgalanmaları (Voltage fluctuations) (7) Frekans değişimleri (Power frequency variations) olarak siralanır [3].

Belirtilen güç kalitesi olayları elektriğin üretim, iletim, dağıtım ve son kullanıcı tarafinda sistem verimliliğinin düşmesine, ekipman ömrünün azalmasına, enerji kayıplarının ve arıza sıklığının artmasına buna bağlı olarak finansal kayıplara neden olmaktadır. Endüstri özelinde bakıldığında üretimin durması, koruma ve koordinasyonun istenilen düzeyde sağlanamaması, motorların beklenen performansta çalışamaması, sürücülerin devreden çıkması ve bu nedenlere bağlı olarak oluşan tüm kayıplar ise üretim verimliliğini etkiler [2]. Güç kalitesi problemlerinin azaltılabilmesi için öncelikle güç parametrelerinin izlenmesi ve anlamlandırılması gereklidir. Elektrik güç parametrelerinin takibinde enerji izleme sistemleri yaygın olarak kullanılmakta ancak gerçekleşen güç kalitesi problemlerinin anlık olarak kayıt altına alınabilmesi ekonomik açıdan maliyetli ve uygulama açısından zorludur. $\mathrm{Bu}$ zorlukları aşmak adına gelişen nesnelerin interneti teknolojisinden yararlanarak belirli standartlara bağlı daha ekonomik ve veri odaklı analizler sağlayacak çözümler kullanılmalıdır. Literatürde yapılan çalışmalar incelendiğinde nesnelerin interneti tabanlı sıcaklık ve nem görüntüleme çözümlerinin mini bilgisayarlar üzerinden yürütülen açık kaynaklı kodlarla yapıldığ 1 görülmektedir [13]. Geçmiş çalışmalarda nesnelerin interneti teknolojisi kullanılarak otomatik aydınlatma-kontrol sistemleri tasarlanmış ve enerjinin verimli kullanımına yönelik çalışmalar yapılmıştır [14]. Son dönemde akıllı evlerde enerji yönetimi başlı̆̆ ile güç parametrelerinin mobil cihazlarla bulut altyapısını kullanarak izlenmesi üzerine çalışmalar yürütülmüştür [15]. Bu çalışmalar güç parametrelerinin analizinin farklı yelpazelerde değerlendirilmesi üzerine yeni çalışmaları olumlu yönde desteklemektedir. Çalışmaların devamında güç parametrelerinin geniş bir yelpazede analiz edilmesi ile belirli güç problemleri daha hızlı ve yatırım maliyeti daha düşük sistemlerle tespit edilebilmesi sağlanabilmektedir. İlk aşama olarak güç kalitesi problemlerinin tespiti için ekipman maliyetleri azaltılmalıdır. Veri odaklı güç kalitesi analizlerinin bulut tabanlı sunucularda depolanması sayesinde belirli bir zaman periyodu sonunda büyük veri analitiği yapılarak verilerden daha fazla katma değerli sonuçlar çıkarılabilecektir. 
Güç kalitesi bozulmalarını daha net ifade etmek adına standartlar bulunmaktadır. International Electrotechnical Commission (IEC) tarafindan yayınlanan IEC 61000-2-5 ve Institute of Electrical and Electronics Engineer (IEEE) tarafından yayınlanan IEEE 1159 standartları, güç kalitesi olaylarının sinıflandırılmasında evrensel olarak kabul gören standartlardır [4]. IEEE 1159-2009 standartları incelendiğinde güç kalitesi bozulmalarının toplandığı başlıklar; geçici olaylar, kısa süreli RMS değişimleri, uzun süreli RMS değişimleri, dengesizlikler, dalga şekli bozuklukları, gerilim dalgalanmaları ve frekans değişimleri olarak belirtilmekte ve güç kalitesi bozulmaları ilgili standartta detaylandırılmaktadır [3]. Güç kalitesi bozulmalarının tespiti ve sınıflandırılmasında farklı yöntemler mevcut olup bu yöntemler güç kalitesi olayının türü, zaman aralığı ve uygulama alanı gibi farklı ihtiyaçlara göre kullanılmaktadır. Güç kalitesi bozulmalarının tespit edilmesi için gerekli donanımların maliyeti yüksek olup uygulamanın gerçekleştirilmesi ise oldukça zorludur. Bu sebeple endüstride ve binalarda belirli zaman aralıklarında güç kalitesi ölçüm cihazları ile yapılan ölçüm sonuçları üzerinden yorumlama ve arıza analizleri yapılmakta fakat uzun süreli durumlarda, şartlardaki değişkenlikler nedeniyle sonuçlar sürdürülebilir olmamaktadır. Gelişen Nesnelerin İnterneti teknolojisi ile daha düşük maliyetli enerji izleme sistemleri geliştirilmekte olup bu teknolojiler elektrik ekipmanlarının gerçek zamanlı izlenmesinde kullanılmaktadır [5,6]. Aynı zamanda tek kartlı mini bilgisayarların düşük maliyetli oluşu ve kodlama ara yüzü kolaylığı sebebiyle bu bilgisayarlar güç kalitesi uygulamalarında donanım ve yazılım odaklı görevler için yaygın olarak kullanılmaktadır [7]. Mini bilgisayarlar üzerinde çalıştırılan algoritmalar ile sahadaki enerji ölçüm cihazlarından alınan güç kalitesi parametreleri sayesinde güç kalitesi bozulmalarını tespit edebilir ve problem ortaya çıktı̆̆ında kayıt işlemi yapılarak ilgili kayıtları bulut (cloud) tabanlı sunuculara gönderebilmektedir. Bu makalede Raspberry Pi 3 B+ mini bilgisayar kullanılarak Siemens SENTRON PAC 3200 enerji analizörünün ölçüm aldığı güç parametrelerinin (akım, gerilim, enerji vb.) değerlendirilmesi, belirli uzun süreli RMS değişimleri ve gerilim-akım dengesizliklerinin anlık tespit edilmesi ve bu analizlerin bulut tabanlı sunuculara aktarılmasıyla sahada gerçekleşen arızaların anlık kayıt altına alınması sağlanmaktadır. Biriken veriler detaylı analizler için kullanılabilmektedir. Böylece büyük veri analitiği ile makine ve ekipman performans1 optimize edilerek enerji verimliliği artırılabilmektedir [8]. Şekil 1' de gösterilen IEEE 1159-2009 standardına göre güç kalitesi problemleri ve makalede incelenen uzun süreli RMS değişimlerinden kaynaklanan güç kalitesi problemlerini belirtmektedir [9].

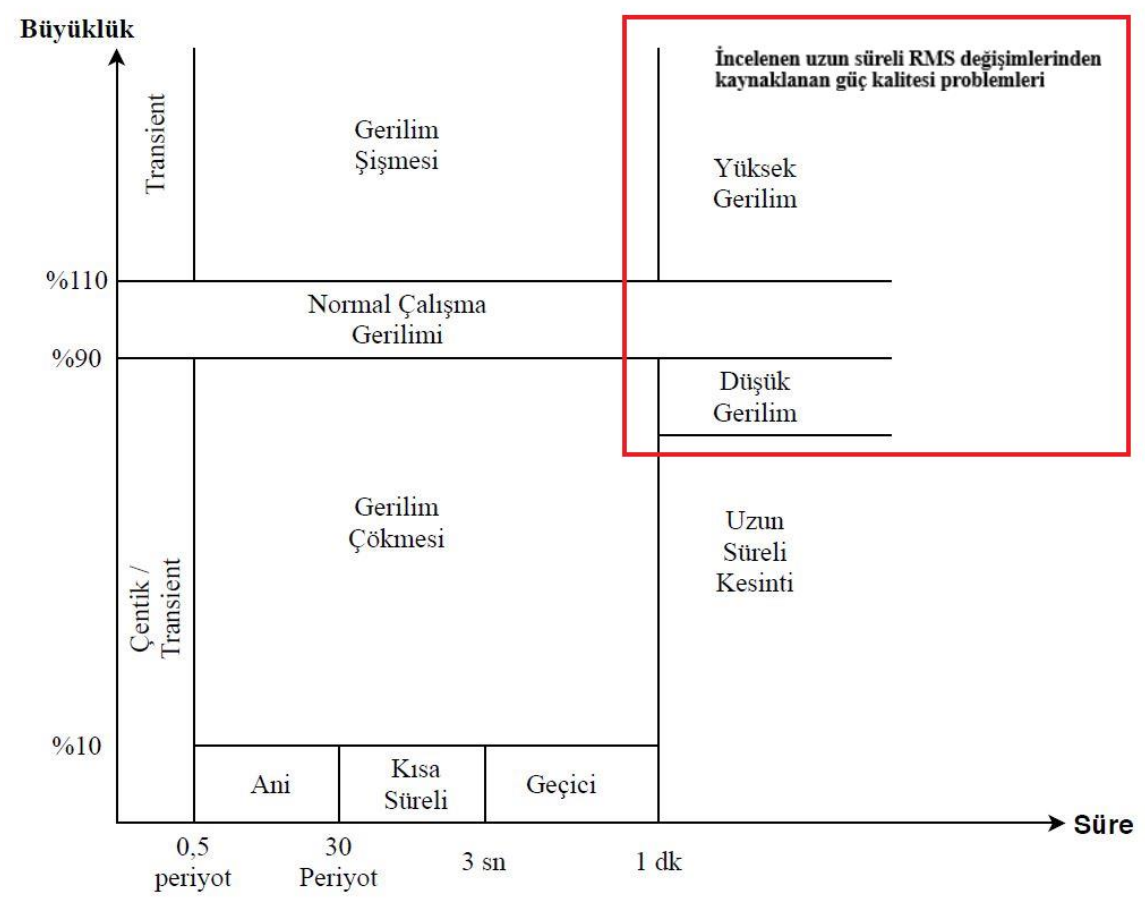

Şekil 1. IEEE 1159-2009 standardına göre güç kalitesi problemleri ve makalede incelenen uzun süreli RMS değişimlerinden kaynaklanan güç kalitesi problemleri 
Bu çalışmada mini bilgisayar olarak kullanılan Raspberry Pi 3B+ güç kalitesi bozulmalarını tespit eden algoritmanın çalıştırıldığı cihazdır. Sahada güç kalitesi analizi yapılacak noktadan güç parametrelerinin ölçümünü yapmak için Siemens SENTRON PAC 3200 enerji analizörü kullanılmıştır. Bu enerji analizöründen veriler Modbus RTU haberleşme protokolü aracılığıyla alınmaktadır. Alınan veriler RPI RS 485 / USB dönüştürücü elektronik devre ile Raspberry Pi 3B+' ye aktarılır. PAC 3200 enerji analizöründen alınan veriler Raspberry Pi 3B + mini bilgisayar üzerinde çalıştırılan algoritma aracılığıyla belirli sıklıkla okunur. IEEE 1159-2009 standardı baz alınarak yazılan analiz algoritması ile yakalanan güç kalitesi bozulmaları kayıt altına alınarak belirli aralıklarla bulut tabanlı sunuculara aktarılır. Verinin her geçen gün daha da önemli hale geldiği günümüzde nesnelerin internetine dayalı düşük yatırım maliyetli çözümler sayesinde sistem verimlilikleri artırılabilmektedir. Gerçekleştirilen uygulamada test edilen tesiste bulunan mevcut sisteme göre yeni tasarlanan sistem sayesinde \%47,15 oranında daha ekonomik bir yatırım maliyeti ile güç kalitesi problemleri tespit edilebilmiştir.

\section{MATERYAL VE METOT}

Çalışmada uzun süreli RMS değişimlerinden kaynaklanan güç kalitesi problemleri (düşük ve yüksek gerilim), akım-gerilim dengesizlikleri ve problem oluştuğu andaki güç kalitesi parametreleri (akım, gerilim vb.) kayıt altına alarak bulut tabanlı sunucuların veri tabanına aktarılmaktadır. Çalışmada ilgili ölçüm noktasındaki elektrik parametrelerini okumak amacıyla Siemens'in SENTRON PAC 3200 enerji analizörü, RS 485 / USB dönüştürücü kart ve Raspberry Pi 3 B+ mini bilgisayar kullanılmıştır. Python programlama dili kullanılarak Raspberry Pi 3 B+ üzerinde çalıştırılan algoritma sayesinde belirli uzun süreli RMS değişimleri ve akım-gerilim dengesizliklerinden kaynaklanan güç kalitesi problemlerinin oluştuğu anda ilgili tüm parametreleri kayıt altına alarak bulut tabanlı sunuculara aktarır. Çalışmada kullanılan ekipmanlar Tablo 1'de belirtilmiştir. Şekil 2'de çalışmada kullanılan ekipmanların ayrı ayrı gösterilmektedir.

Tablo 1. Çalışmada kullanilan ekipmanlar

\begin{tabular}{cc}
\hline Kullanılan Ekipman & Adet \\
\hline Siemens PAC 3200 Enerji & 1 \\
Analizörü & \\
Raspberry Pi 3B + Mini Bilgisayar & 1 \\
RS 485/USB Dönüştürücü & 1 \\
\hline
\end{tabular}

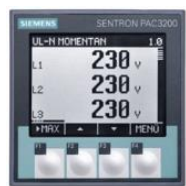

(a)

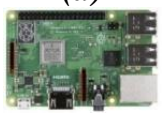

(b)

(c)

Şekil 2. (a) Siemens PAC 3200 Enerji Analizörü, (b) Raspberry Pi 3B + Mini Bilgisayar ve (c) RS 485/USB Dönüştürücü

PAC 3200 cihazı 50'den fazla temel elektrik parametrelerinin (akım, gerilim, enerji, vb.) ölçümünü yapabilen endüstriyel güç izleme cihazıdır. PAC 3200 enerji analizörü Modbus RTU/TCP ve Profibus DP haberleşme protokollerini desteklemektedir. Modbus haberleşme protokolü Modicon tarafindan 1979 yılında tasarlanan açık erişim protokolü olup endüstriyel haberleşmede yaygın olarak kullanılır [10]. Modbus versiyonlarına bakıldığında Modbus RTU, ASCII ve Modbus TCP/IP farklı tip 
haberleşme ihtiyaçları için kullanılmaktadır. Çalışmada Modbus RTU haberleşme altyapısı kayıt (register) okumak için kullanılır. Modbus RTU haberleşme protokolü alt yapısında ana cihaz (master) ve bağımlı cihaz (slave) arasındaki iletişim sorgu-yanıt metodu ile sağlanmaktadır. Ana cihazın gönderdiği sorguya bağımlı cihaz cevap vermektedir [10]. Çalışmada ana cihaz olarak Raspberry Pi 3B+ kullanılmakta olup bağımlı cihaz olarak PAC 3200 enerji analizörü kullanılmıştır. Raspberry Pi'ın verileri alabilmesi için USB portu mevcut olup PAC 3200'ün Modbus RTU RS 485-a ve 485-b uçlarından alınan sinyal RS485/USB dönüştürücü kart ile dönüştürülerek Raspberry Pi 3 B+'a aktarılır. Güç kalitesi bozulmalarının kayıt altına alınabilmesi için geliştirilen algoritma akış diyagramı şekil 3'de gösterilmiştir.

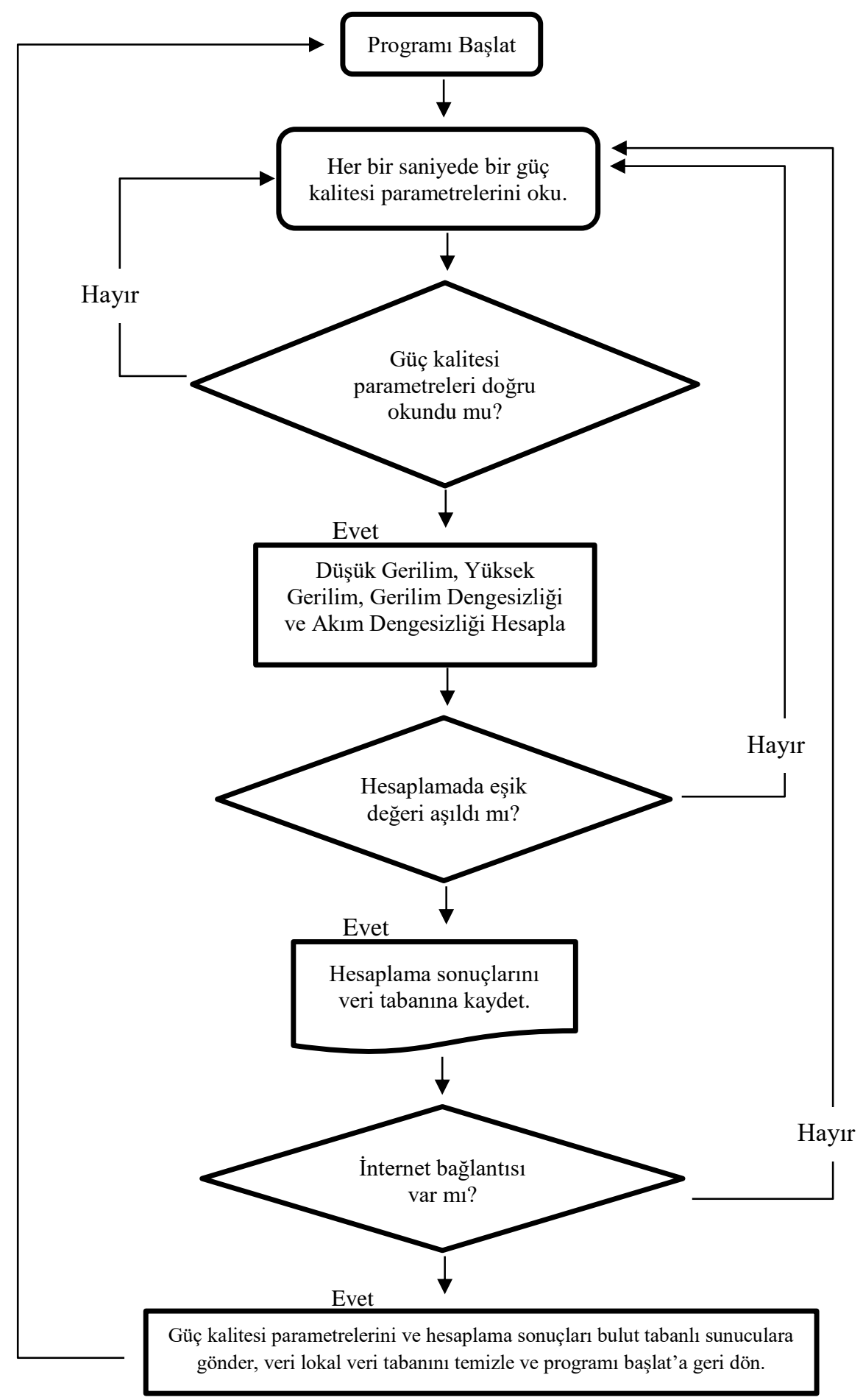

Şekil 3. Algoritmanın akış diyagramı 
Tablo 2'de Raspberry Pi 3 B+ üzerinde geliştirilen algoritma ile 23 adet modbus adres kaydı anlık olarak okunmaktadır. Algoritmada modbus adres kayıtlarının okunmasında açık kaynak kodlu pymodbus kütüphanesi kullanılmıştır.

Tablo 2. PAC 3200 Enerji Analizöründen Okunan Modbus Adres Değerleri

\begin{tabular}{|c|c|c|c|c|c|}
\hline Ofset & Adres Sayısı & Parametre & Format & Birim & Değer Aralığı \\
\hline 1 & 2 & Gerilim_L1-N & Float & $\mathrm{V}$ & - \\
\hline 3 & 2 & Gerilim_L2-N & Float & V & - \\
\hline 5 & 2 & Gerilim_L3-N & Float & V & - \\
\hline 7 & 2 & Gerilim_L1-L2 & Float & V & - \\
\hline 9 & 2 & Gerilim_L2-L3 & Float & V & - \\
\hline 11 & 2 & Gerilim_L3-L1 & Float & $\mathrm{V}$ & - \\
\hline 13 & 2 & Akım_L1 & Float & A & - \\
\hline 15 & 2 & Ak1m_L2 & Float & A & - \\
\hline 17 & 2 & Akım_L3 & Float & $\mathrm{A}$ & - \\
\hline 43 & 2 & THD-R Gerilim_L1 & Float & $\%$ & $0 \ldots 100$ \\
\hline 45 & 2 & THD-R Gerilim_L2 & Float & $\%$ & $0 \ldots 100$ \\
\hline 47 & 2 & THD-R Gerilim_L3 & Float & $\%$ & $0 \ldots 100$ \\
\hline 49 & 2 & THD-R Akım_L̄1 & Float & $\%$ & $0 \ldots 100$ \\
\hline 51 & 2 & THD-R Ak1m_L2 & Float & $\%$ & $0 \ldots 100$ \\
\hline 53 & 2 & THD-R Akım_L3 & Float & $\%$ & $0 \ldots 100$ \\
\hline 55 & 2 & Şebeke Frekansı & Float & $\mathrm{Hz}$ & $45 \ldots 65$ \\
\hline 801 & 4 & Aktif Enerji & Double & Wh & $\begin{array}{c}\text { Overflow } \\
1.0 \mathrm{e}+12\end{array}$ \\
\hline 817 & 4 & İndüktif Enerji & Double & Varh & $\begin{array}{c}\text { Overflow } \\
1.0 \mathrm{e}+12\end{array}$ \\
\hline 825 & 4 & Kapasitif Enerji & Double & Varh & $\begin{array}{c}\text { Overflow } \\
1.0 \mathrm{e}+12\end{array}$ \\
\hline 37 & 2 & Güç Faktörü_L1 & Float & - & $0 \ldots 1$ \\
\hline 39 & 2 & Güç Faktörü_L2 & Float & - & $0 \ldots 1$ \\
\hline 41 & 2 & Güç Faktörü_L3 & Float & - & $0 \ldots 1$ \\
\hline 69 & 2 & Toplam Güç Faktörü & Float & - & $0 \ldots 1$ \\
\hline
\end{tabular}

\section{A. HESAPLAMA ALGORITMASI}

Çalışmada geliştirilen algoritma sayesinde uzun süreli RMS değişimlerinden kaynaklanan düşük gerilim, yüksek gerilim hesaplanması ile akım ve gerilim dengesizliği hesaplanmaktadır.

\section{A. 1. Düşük Gerilim ve Yüksek Gerilim Hesaplaması}

IEEE'nin 1159-2009 standardında belirtilen uzun süreli RMS değişimleri kaynaklı düşük gerilim problemi; güç frekansında nominal gerilim seviyesinin 1 dakikadan fazla süre boyunca $\% 80$ ile $\% 90$ arasında bir değer alması, yüksek gerilim problemi ise; güç frekansında nominal gerilim seviyesinin 1 dakikadan fazla süre boyunca $\% 110$ ile $\% 120$ arasında bir değer alması olarak tanımlanmaktadır [4]. Geliştirilen algoritmada düşük ve yüksek gerilim hesabını kaba-kod (pseudo code) aracılığıyla açıklanabilir.

Düşük gerilim hesabının kaba kod aracılı̆̆ıyla davranışı; 
$\mathrm{Bu}$ algoritma uzun süreli RMS değişimlerinden kaynaklanan düşük gerilim probleminin tespitinde kullanılmaktadır. $\mathrm{V}_{\mathrm{L} 1}$ : L1 fazına ait gerilim değerini, $\mathrm{V}_{\mathrm{L} 2}$ : L2 fazına ait gerilim değerini, $\mathrm{V}_{\mathrm{L} 3}$ : L3 fazına ait gerilim değerini göstermektedir.

1. $\mathrm{V}_{\mathrm{L} 1}, \mathrm{~V}_{\mathrm{L} 2}, \mathrm{~V}_{\mathrm{L} 3}$ ve nominal gerilim değerini $\left(\mathrm{N}_{\mathrm{G}}\right)$ oku.

2. Eğer $\mathrm{V}_{\mathrm{L} 1}$ değerleri $\left(\mathrm{N}_{\mathrm{G}} \times 0,9\right)$ değeri ile $\left(\mathrm{N}_{\mathrm{G}} \times 0,8\right)$ değerleri arasında veya bu değerlere eşitse,

3. Düşük gerilim sayacına $+=$ " 1 " yaz ve her döngüde koşul sağlanıyorsa sayacı " +1 " arttır.

4. Eğer düşük gerilim sayac1 60 değerine eşitse düşük gerilim değerine $\left.\left(V_{L 1}-N_{G}\right) \times 100 / N_{G}\right)$ işleminin mutlak değerini yaz ve düşük gerilim sayacı sıfırlanana kadar her döngüde bir veri tabanına bu değeri kaydet.

5. Eğer $V_{L 1}$ değerleri $\left(N_{G} \times 0,9\right)$ değeri ile $\left(N_{G} \times 0,8\right)$ değerleri arasında değilse düşük gerilim sayacına " 0 " ata ve düşük gerilim değerine " 0 " ata.

6. $\mathrm{V}_{\mathrm{L} 2}, \mathrm{~V}_{\mathrm{L} 3}$ değerleri içinde $\mathrm{V}_{\mathrm{L} 1}$ için gerçekleştirilen döngünün aynısını tekrarla.

7. Bu döngüyü her değer okuma çevrim süresi boyunca tekrarla.

Yüksek gerilim hesabının kaba kod aracılığıyla davranışı;

$\mathrm{Bu}$ algoritma uzun süreli RMS değişimlerinden kaynaklanan yüksek gerilim probleminin tespitinde kullanılmaktadır. VL1: L1 fazına ait gerilim değerini, VL2: L2 fazına ait gerilim değerini, VL3: L3 fazına ait gerilim değerini göstermektedir.

1. $\mathrm{V}_{\mathrm{L} 1}, \mathrm{~V}_{\mathrm{L} 2}, \mathrm{~V}_{\mathrm{L} 3}$ ve nominal gerilim değerini $\left(\mathrm{N}_{\mathrm{G}}\right)$ oku.

2. Eğer $\mathrm{V}_{\mathrm{L} 1}$ değerleri $\left(\mathrm{N}_{\mathrm{G}} \times 1,1\right)$ değeri ile $\left(\mathrm{N}_{\mathrm{G}} \times 1,2\right)$ değerleri arasında veya bu değerlere eşitse,

3. Yüksek gerilim sayacına $+=$ "1" yaz ve her döngüde koşul sağlanıyorsa sayacı " +1 " arttır.

4. Eğer yüksek gerilim sayacı 60 değerine eşitse yüksek gerilim değerine $\left.\left(V_{L 1}-N_{G}\right) \times 100 / N_{G}\right)$ işleminin mutlak değerini yaz ve yüksek gerilim sayacı sıfirlanana kadar her döngüde bir veri tabanına bu değeri kaydet.

5. Eğer $\mathrm{V}_{\mathrm{L} 1}$ değerleri $\left(\mathrm{N}_{\mathrm{G}} \times 1,1\right)$ değeri ile $\left(\mathrm{N}_{\mathrm{G}} \times 1,2\right)$ değerleri arasında değilse yüksek gerilim sayacına " 0 " ata ve düşük gerilim değerine " 0 " ata.

6. $\mathrm{V}_{\mathrm{L} 2}, \mathrm{~V}_{\mathrm{L} 3}$ değerleri içinde $\mathrm{V}_{\mathrm{L} 1}$ için gerçekleştirilen döngünün aynısını tekrarla.

7. Bu döngüyü her değer okuma çevrim süresi boyunca tekrarla.

\section{A. 2. Gerilim-Akım Dengesizliği}

Çalışmada gerilim ve akım dengesizliğinin tespitinde üç fazın gerilim ve akım değerleri ortalamasının maksimum sapma değerinden yararlanılır. Bu yöntemde gerilim ve akım dengesizliğinin miktarı maksimum sapma oranı ile ölçülür ve hesaplanır [11]. Ortalamadan maksimum sapmanın oranı gerilim için sistem kararlı halde iken \%0,5-\%2 arasında olmalıdır. Akım için ise bu değer aralığ $\% 1-\% 30$ arasında olması gerekir. Bu değerler aralıklarının dışında kalan oranlar gerilim ve akım dengesizliğini gösterir. Gerilim ve akım dengesizliği Eşt. 1 ve Eşt. 2'de gösterilmiş̧tir.

$$
\begin{aligned}
& \text { Vdengesizlik } \%=100 \times \frac{\text { Ortalama gerilim değerinden maksimum sapma }}{\text { Ortalama gerilim değeri }} \\
& \text { Idengesizlik }=100 \times \frac{\text { Ortalama akım değerinden maksimum sapma }}{\text { Ortalama akım değeri }}
\end{aligned}
$$

Gerilim-akım dengesizliğinin kaba kod (pseudo code) aracılığıyla davranışı;

$\mathrm{Bu}$ algoritma gerilim ve akım dengesizliklerinin tespitinde kullanılmaktadır. $\mathrm{V}_{\mathrm{L} 1}$ : $\mathrm{L} 1$ fazına ait gerilim değerini, $\mathrm{V}_{\mathrm{L} 2}$ : $\mathrm{L} 2$ fazına ait gerilim değerini, $\mathrm{V}_{\mathrm{L} 3}$ : L3 fazına ait gerilim değerini, $\mathrm{I}_{\mathrm{L} 1}$ : L1 fazına ait akım değerini, IL2: L2 fazına ait akım değerini, IL3: L3 fazına ait akım değerini göstermektedir.

1. $\mathrm{V}_{\mathrm{L} 1}, \mathrm{~V}_{\mathrm{L} 2}, \mathrm{~V}_{\mathrm{L} 3}, \mathrm{I}_{\mathrm{L} 1}, \mathrm{I}_{\mathrm{L} 2}, \mathrm{I}_{\mathrm{L} 3}$ değerlerini oku. 
2. $\mathrm{V}_{\mathrm{L} 1}, \mathrm{~V}_{\mathrm{L} 2}, \mathrm{~V}_{\mathrm{L} 3}$ gerilim değerlerinin aritmetik ortalamasını al ve ortalama gerilim değerine bu değeri yaz.

3. $\mathrm{V}_{\mathrm{L} 1}$ değeri ile ortalama gerilim değeri arasındaki farkın mutlak değerini al, ortalama gerilim değerine böl, 100 ile çarp ve $\mathrm{V}_{\text {Lldengesizlik }}$ değerine yaz.

4. $\mathrm{V}_{\mathrm{L} 2}$ değeri ile ortalama gerilim değeri arasındaki farkın mutlak değerini al, ortalama gerilim değerine böl, 100 ile çarp ve $V_{\text {L2dengesizlik }}$ değerine yaz.

5. $\mathrm{V}_{\mathrm{L} 3}$ değeri ile ortalama gerilim değeri arasındaki farkın mutlak değerini al, ortalama gerilim değerine böl, 100 ile çarp ve $V_{\text {L3dengesizlik }}$ değerine yaz.

6. $\mathrm{V}_{\text {L1dengesizlik }}, \mathrm{V}_{\mathrm{L} \text { 2dengesizlik }}, \mathrm{V}_{\mathrm{L} \text { dengesizlik }}$ değerlerinden en büyük olanını $\mathrm{V}_{\text {dengesizlik }}$ değerine yaz.

7. Eğer $V_{\text {dengesizlik }}$ değişkeni $\% 0,5$ ile $\% 2$ değeri arasında ise aynı işlemi döngü boyunca tekrarla değilse $\mathrm{V}_{\text {dengesizlik }}$ değişkenin diğer okunan tüm güç kalitesi parametreleri ile birlikte veri tabanına yaz.

8. $\mathrm{I}_{\mathrm{L} 1}, \mathrm{I}_{\mathrm{L} 2}, \mathrm{I}_{\mathrm{L} 3}$ akım değerlerinin aritmetik ortalamasını al ve ortalama akım değerine bu değeri yaz.

9. $\mathrm{I}_{\mathrm{L} 1}$ değeri ile ortalama akım değeri arasındaki farkın mutlak değerini al, ortalama akım değerine böl, 100 ile çarp ve $\mathrm{I}_{\mathrm{L} 1 \mathrm{dengesizlik}}$ değerine yaz.

10. $\mathrm{I}_{\mathrm{L} 2}$ değeri ile ortalama akım değeri arasındaki farkın mutlak değerini al, ortalama akım değerine böl, 100 ile çarp ve $\mathrm{I}_{\mathrm{L} 2 \mathrm{dengesizlik}}$ değerine yaz.

11. $\mathrm{I}_{\mathrm{L} 3}$ değeri ile ortalama akım değeri arasındaki farkın mutlak değerini al, ortalama akım değerine böl, 100 ile çarp ve $\mathrm{I}_{\mathrm{L} 3 \mathrm{dengesizlik}}$ değerine yaz.

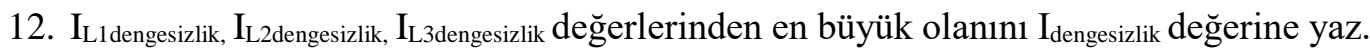

13. Eğer $I_{\text {dengesizlik }}$ değişkeni $\% 1$ ile $\% 30$ değeri arasında ise aynı işlemi döngü boyunca tekrarla değilse $I_{\text {dengesizlik }}$ değişkenin diğer okunan tüm güç kalitesi parametreleri ile birlikte veri tabanına yaz.

14. Bu döngüyü her değer okuma çevrim süresi boyunca tekrarla.

\section{B. HESAPLAMALARIN VERİ TABANINA KAYDEDILMESİ VE BULUT TABANLI SUNUCULARA ENTEGRASYONU}

Hesaplanan verilerin veri tabanına kaydedilmesi için açık kaynak kodlu nesne-ilişkisel işlem yapan PostgreSQL veri tabanı yönetim sistemi kullanılmıştır. PostgreSQL Kaliforniya Üniversitesi Berkeley Bilgisayar Bilimi departmanı tarafından geliştirilmiş olup açık kaynak kodlu ücretsiz bir veri tabanı yönetim sistemidir [12]. Hesaplama algoritmasında yakalanan güç kalitesi problemleri PostgreSQL veri tabanına yazılır. Algoritma 1 dakika da bir internet bağlantısının var olup-olmadığını kontrol ederek internet bağlantısı var ise Hiper metin Trasfer Protokolü (HTTP) komutları ile Raspberry mini bilgisayar ile bulut tabanlı sunucular arasında veri akışı sağlanır. Veri paketi JavaScript Nesnesi Gösterimi (JSON) formatında olup okunabilir bir yapıda iletilir. Şekil 4'te algoritmanın sunuculara gönderdiği veri paketi gösterilmiştir. 


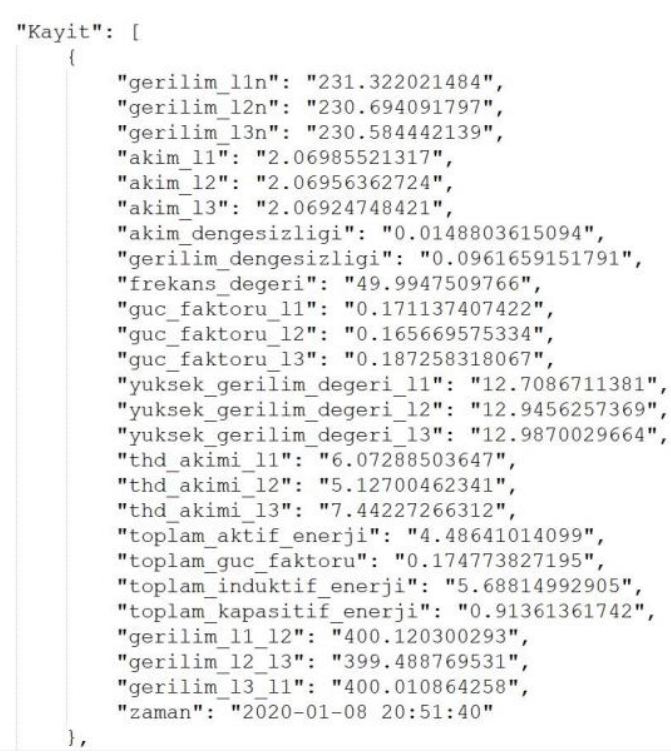

Şekil 4. Algoritmanın sunuculara gönderdiği veri paketi

\section{BULGULAR VE TARTISMA}

Yapılan çalışmada Python programlama dili ile Raspberry Pi 3 B+ mini bilgisayar üzerinde düşük gerilim, yüksek gerilim ve akım-gerilim dengesizliklerinden kaynaklanan güç kalitesi problemlerini tespit eden ve sistemin anlık güç parametreleri ile kayıt altına alınmasını sağlayan algoritma geliştirilmiş ve test edilmiştir. Test işlemi bir fabrikada $2500 \mathrm{kVA}$ gücündeki trafodan beslenen 6 adet MCC panosundan biri olan MCC-2 adlı panonun maksimum akım kapasitesi 2500 amper olan 3 kutuplu otomatik şalter'in çıkışında test edilmiştir. Çıkışa bağlanan PAC 3200 enerji analizöründen Raspberry Pi 3 B+ mini bilgisayar aracılığıyla çalışan algoritma sayesinde veriler alınmış ve buluttaki sunuculara aktarılmıştır. Test işlemi 48 saat boyunca kayıt alınan tüm değerleri her bir dakikada bir bulut tabanlı sunuculara göndermiştir. Test verileri sunulardan çekilerek grafik haline getirilmiş ve sonuçlar incelenmiştir. Şekil 5'te test işleminde her bir L1, L2, L3 fazı için gerilim ölçüm değerleri gösterilmiştir. Tüm fazlar incelendiğinde gerilim değeri 221,71 volt ile 231,22 volt arasında ölçülmüştür. Şekil 6 'da her bir L1, L2, L3 fazı için akım ölçüm değerleri gösterilmekte olup grafikte cl1n ifadesi L1 fazını, cl2n ifadesi L2 fazını ve cl3n ise L3 fazının akım değerlerini göstermektedir. L1 faz1 973,13 A'e kadar L2 fazı 1478,22 A'e kadar ve L3 fazı ise 953,41 A'e kadar değişim göstermiştir. Şekil 7'de frekans ölçüm değerleri gösterilmiştir. Frekans değeri 49,92 Hz ile 50,09 Hz arasında salınım göstermiştir. 


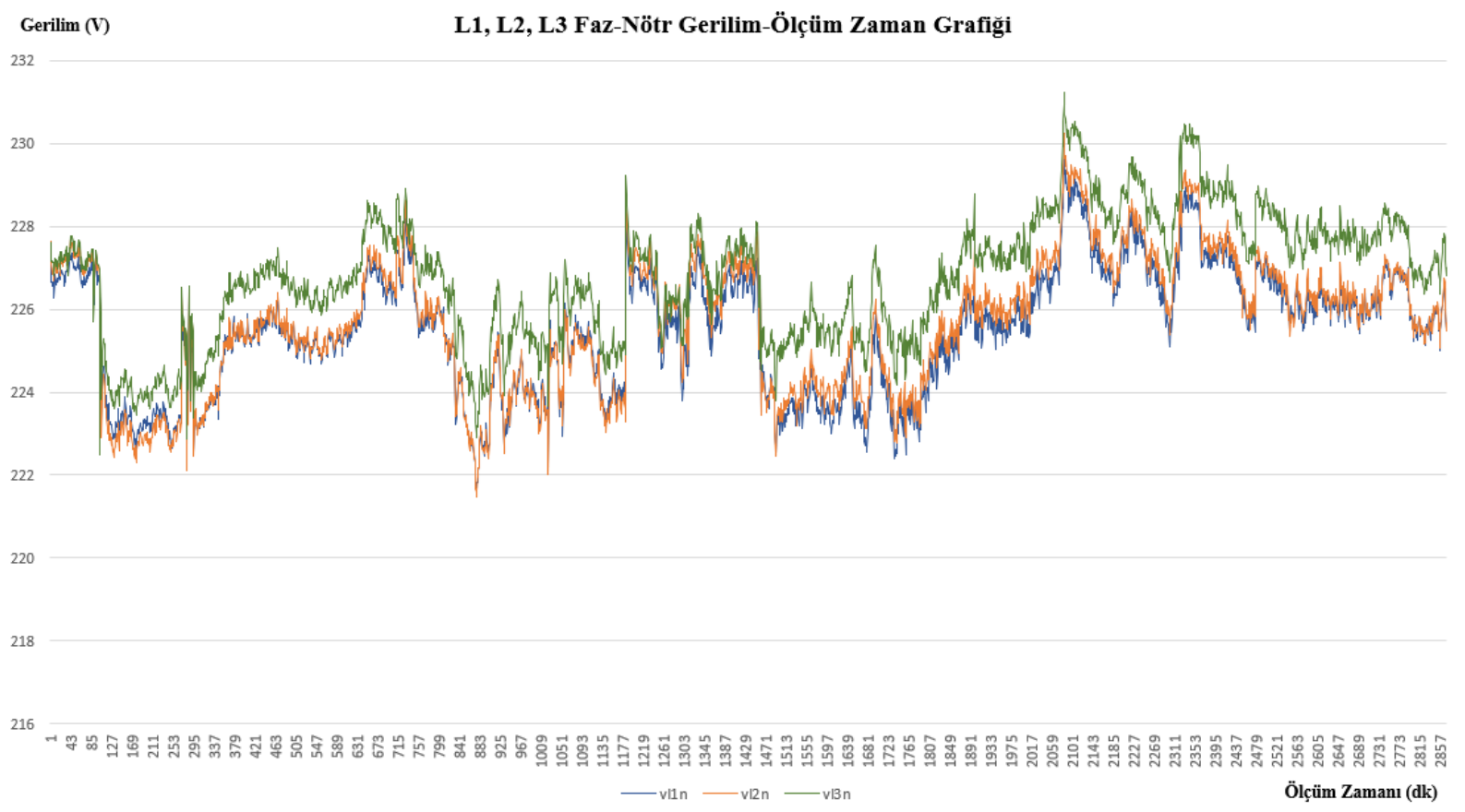

Şekil 5. L1, L2, L3 faz-nötr gerilimlerinin ölçüm değerleri
Akm (A)
L1, L2, L3 Faz-Nötr Akımları-Ölçüm Zaman Grafiği

1600

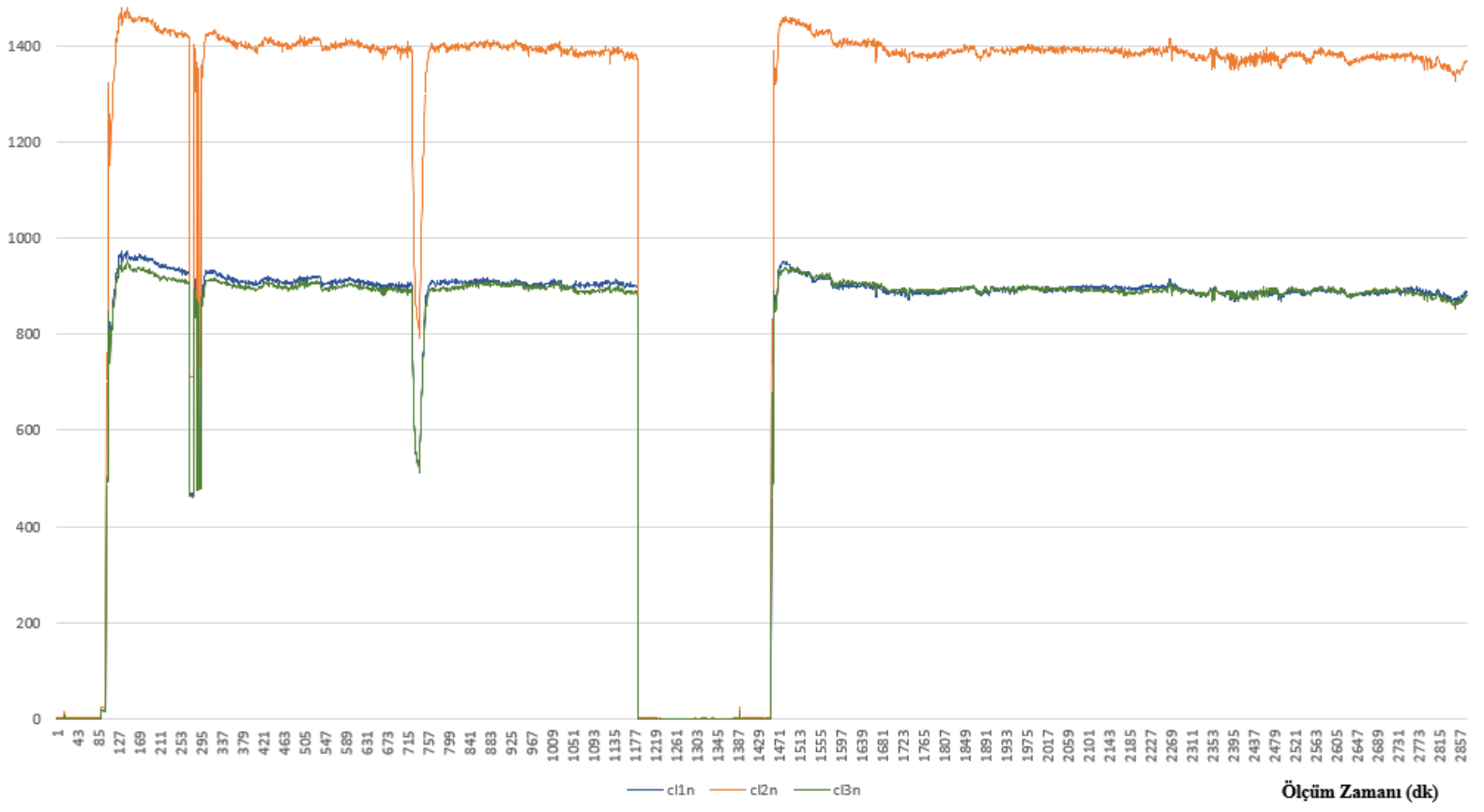

Şekil 6. L1, L2, L3 faz-nötr akımlarının ölçüm değerleri 


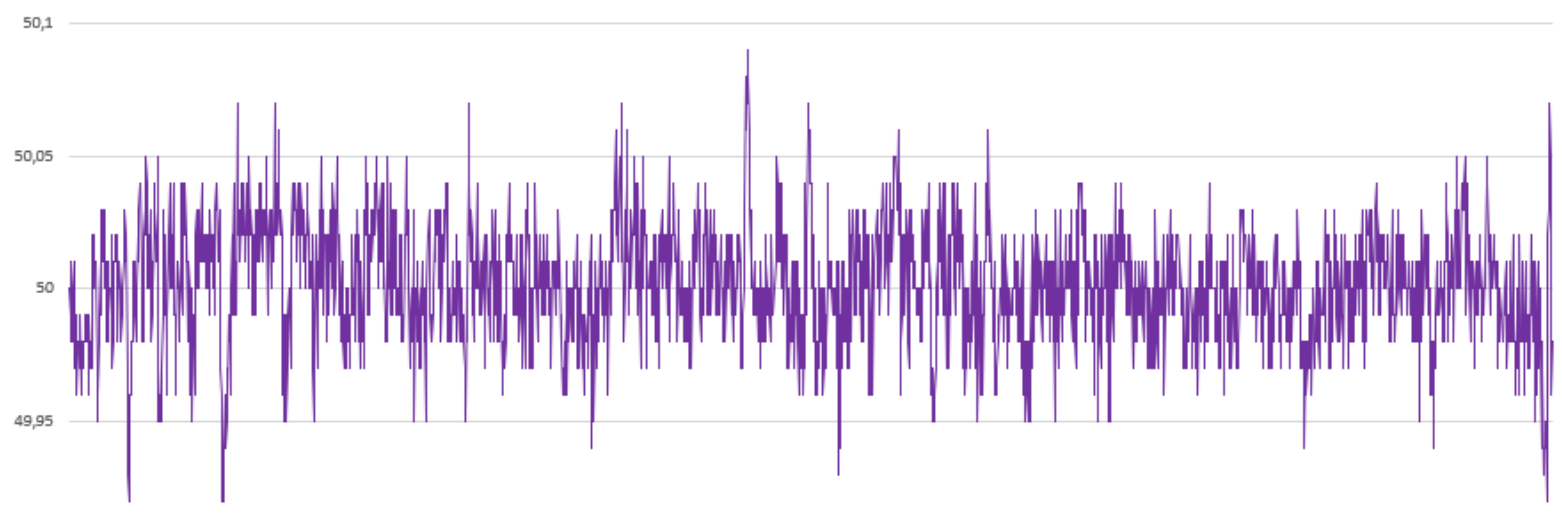

49,9

49,85

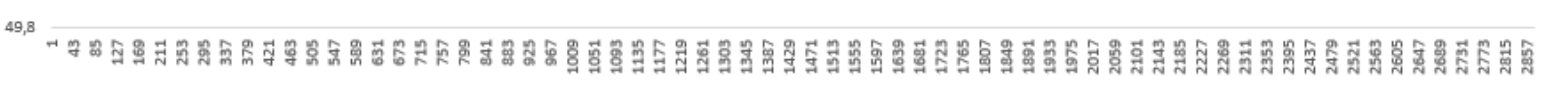

Ölçüm Zamanı (dk)

Şekil 7. L1, L2, L3 frekanslarının ölçüm değerleri

Şekil 8'de L1, L2 ve L3 fazlarında gerilim dengesizliği verileri grafikte gösterilmiştir. Şekil 8 incelendiğinde sistemde gerilim dengesizlik oranları $\% 0,5$ ile $\% 2$ sınırlarının içinde yer almakta olup sistemde gerilim dengesizliği problemi olmadığı saptanmıştır. Şekil 9'da L1, L2 ve L3 fazlarında akım dengesizliği verileri grafikte gösterilmiştir. Şekil 9 incelendiğinde sistem normal çalışma durumunda L1 ve L3 fazlarının akım dengesizliği, sınır değerleri olan \%1-\%30 arasında olduğu saptanmıştır. L2 fazı incelendiğinde sistem normal çalışma durumunda akım dengesizlik oranları olması gereken sınırların üstünde olarak \%30,02 ile \%31,81 değerleri arasında ölçülmüştür. Sistemin çalışma süresi 48 saatlik periyotta incelendiğinde belirli periyotlarda devam eden akım dengesizliği problemi mevcuttur. Geliştirilen algoritma ile sahada akım dengesizliği probleminin tespit edildiği anda diğer güç parametreleri ile kayıt altına alınması arıza kaynağını bulmakta önemli ipuçları sunmaktadır. Çoğu zaman geleneksel enerji izleme altyapıları ile sahadan gelen veriler sadece görsel olarak okunmaktadır ancak yeni gelişen teknolojilerin kullanımı ile sorunların daha hızlı tespit edilmesi sağlanır. Günümüzde izleme noktalarının sayısı ve takip edilen veri tipleri ne kadar artırılabilirse problemlerin çözümlenmesi o denli hızlı olacaktır. Bu yapıların gelişmesi içinde yatırım maliyeti düşük sistemler ve esnek yapıların hayata geçirilmesi sağlanabilir. 


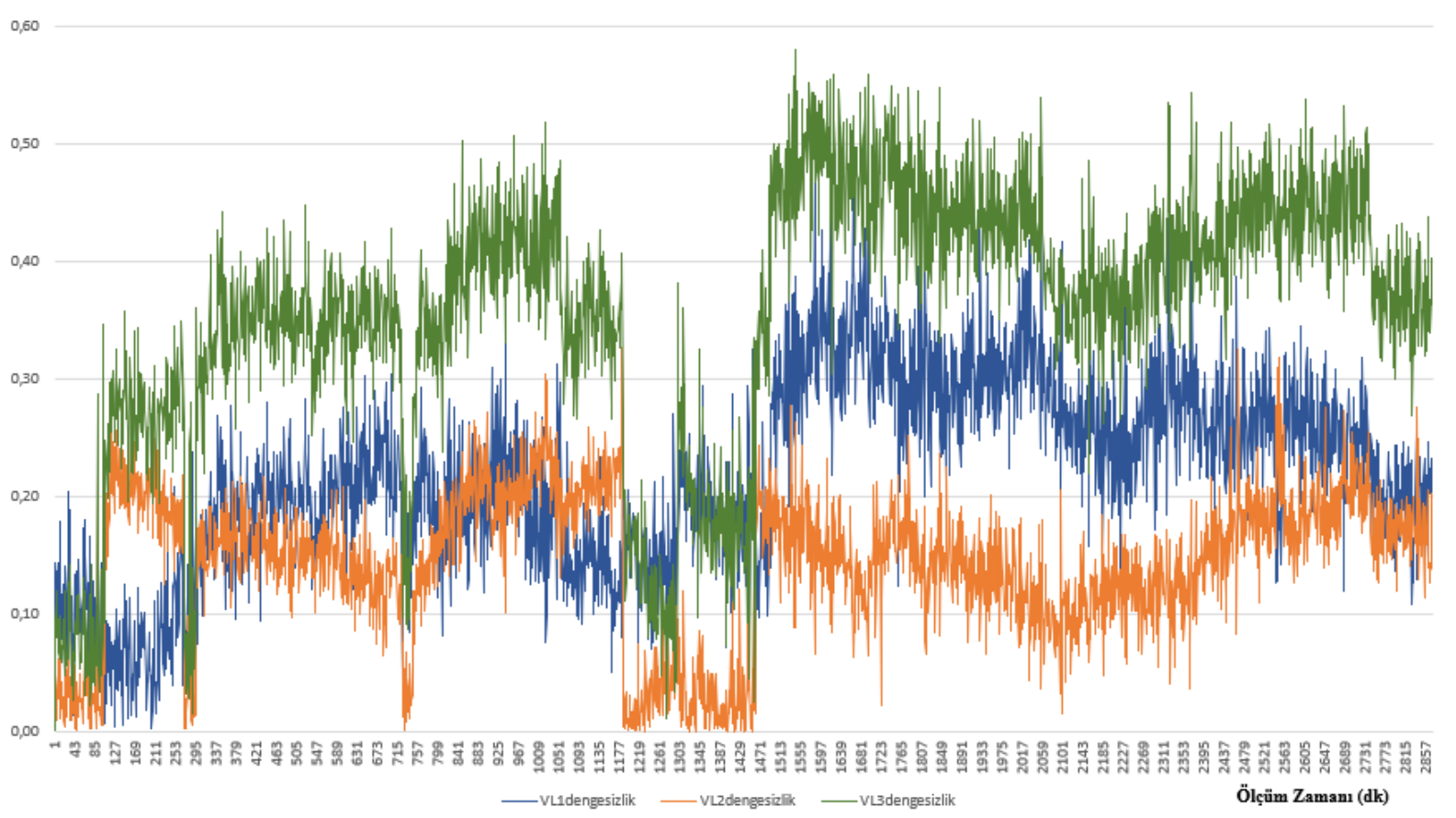

Şekil 8. L1, L2, L3 gerilim dengesizlik oranlarının ölçüm değerleri

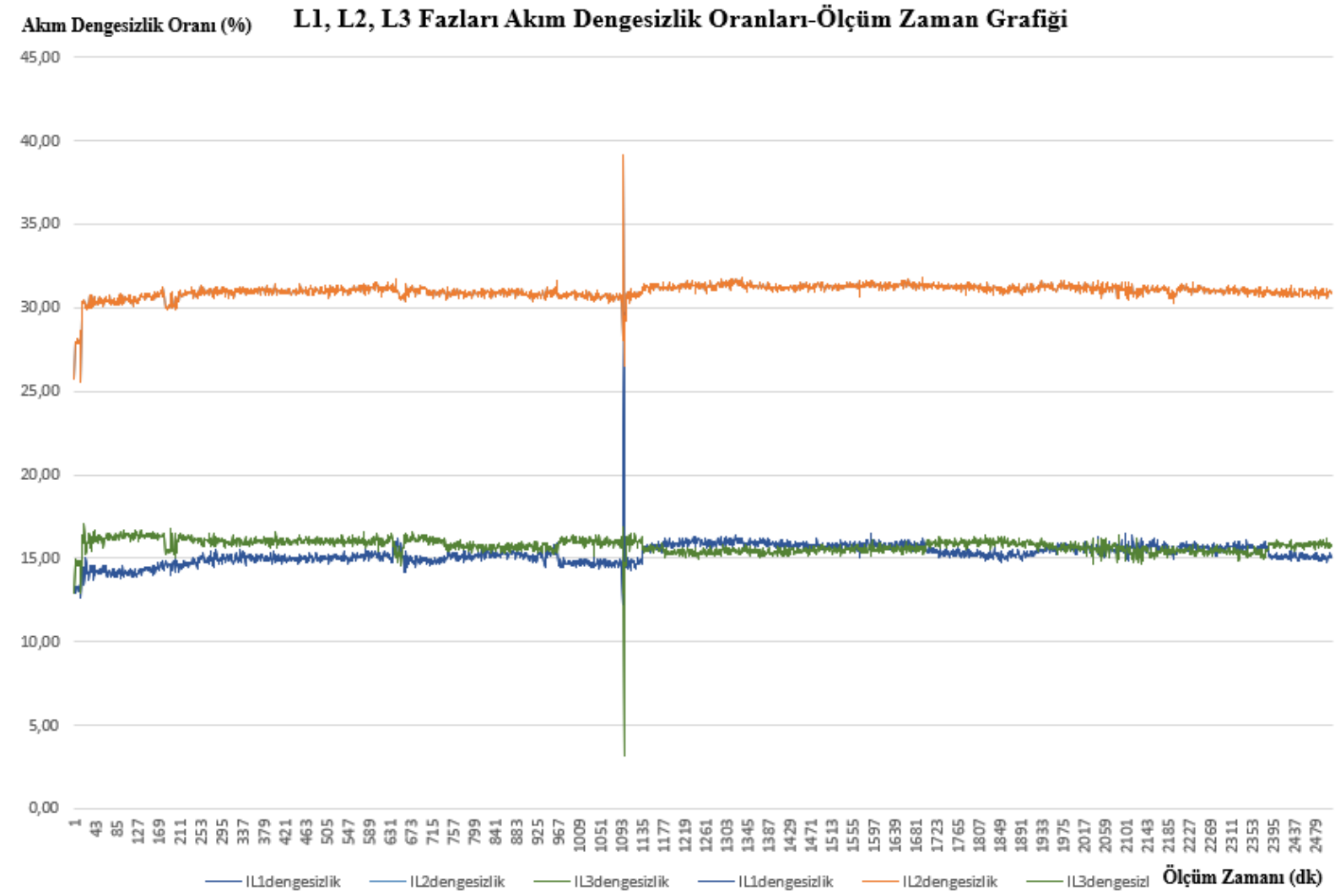

Şekil 9. L1, L2, L3 akım dengesizlik oranlarının ölçüm değerleri 
Sistemde ölçüme başlanmadan önce algoritmada yer alan nominal gerilim değeri $\left(\mathrm{N}_{\mathrm{G}}\right) 220$ volt değerine ayarlanmıştır. Sistem için $50 \mathrm{~Hz}, 220$ volt gerilim seviyesi nominal çalışma gerilimi koşulunu ifade etmektedir. Şekil 10'da her bir faz için yüksek gerilim test verileri grafikte gösterilmiştir. Şekil 10'da veriler incelendiğinde çalışma gerilimi \%110'un üstüne çıkmamış yani değişim yüksek gerilim oranı \%10'un üstüne çıkmamıştır. En yüksek ölçülen yüksek gerilim oranı L3 fazında \%5,10 değerinde olup bu değerin karşıllı̆ı nominal gerilimin \%105,10’una denk gelmektedir.

Sistemden alınan ölçüm değerlerinde 220 volt gerilim değerinin altında bir ölçüm alınmamıştır. $\mathrm{Bu}$ sebeple düşük gerilim tespit edilmemiştir.

Yülselc Gerilim Oram (\%) L1, L2, L3 Fazları Yüksek Gerilim Oranı - Ölçüm Zaman Grafiği

5,00

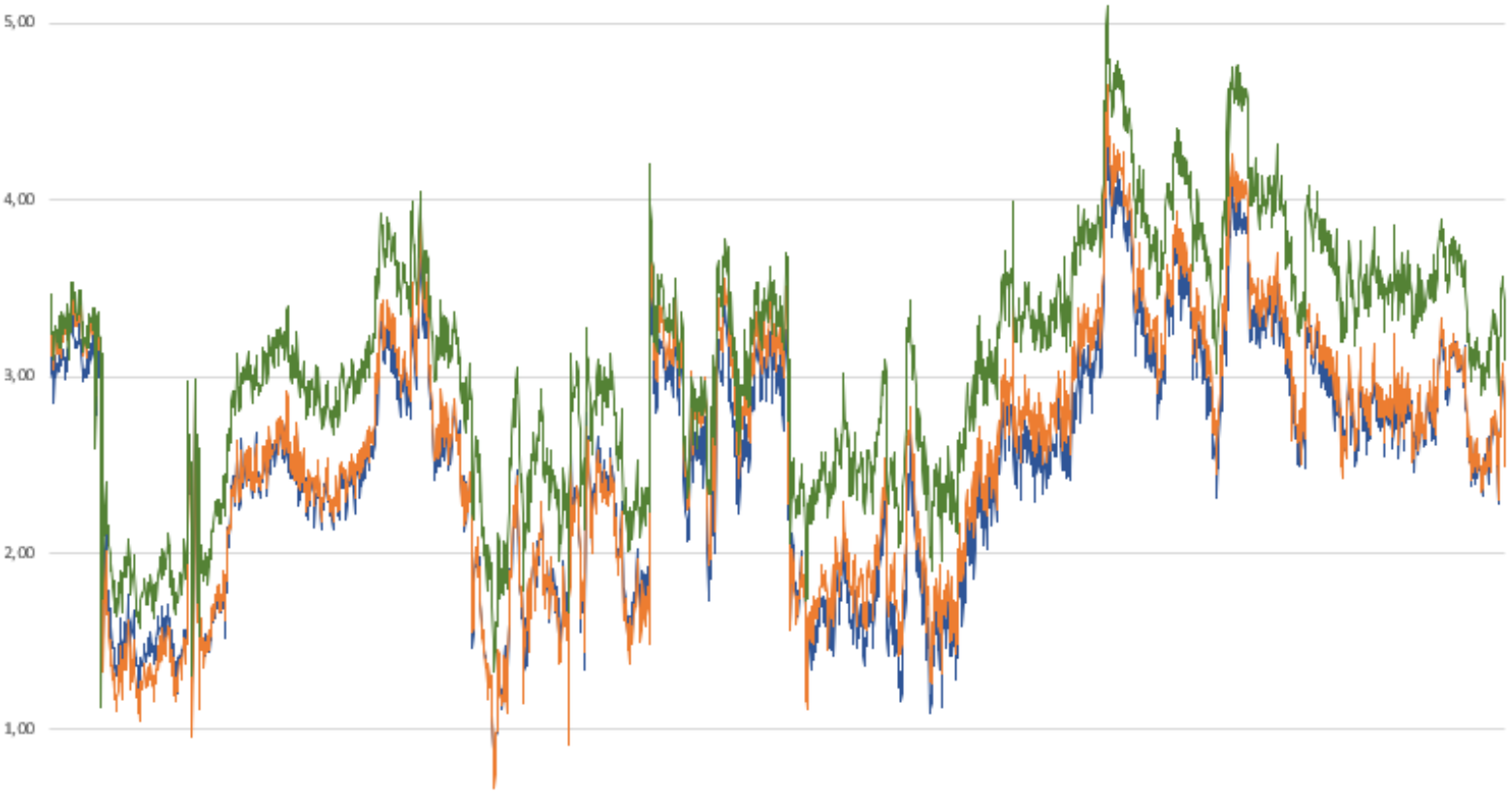

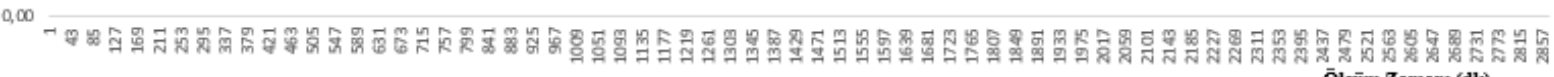

—YüksekGerilim_L1 —YüksekGerilim_L2 -YüksekGerilim_t3

Ölçūm Zamam (dk)

Şekil 10. L1, L2, L3 fazları yüksek gerilim oranlarının ölçüm değerleri 
Tablo 3'te gösterilen veriler, işletmelerde yaygın olarak kullanılan mevcut sistemlerin ekipman maliyetlerine ve tasarlanan sistem ekipman maliyetlerini göstermektedir. Geleneksel mevcut sistem ekipman maliyetleri izleme noktası başına 13,34 \$'lık yatırım maliyeti gerektirirken, tasarlanan sistemle nesnelerin interneti ve bulut teknolojileri kullanılarak izleme noktası başına yatırım maliyeti 7,05 \$’a kadar düşürülebilir. Bu sayede \%47,15 oranında yatırım maliyetinden tasarruf sağlanmaktadır.

Tablo 3. Mevcut Sistem ile Tasarlanan Sistem Maliyet Klyaslaması

\begin{tabular}{|c|c|c|c|}
\hline & Ekipmanlar & Değer & Kaynak \\
\hline \multirow{4}{*}{ 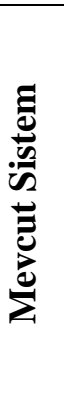 } & PLC CPU & \multirow{4}{*}{$\begin{array}{l}13,34 \$ \text { / } \\
\text { izleme } \\
\text { noktas } 1\end{array}$} & \multirow{4}{*}{$\begin{array}{l}\text { Siemens Endüstriyel } \\
\text { Otomasyon Listesi } \\
{[16]}\end{array}$} \\
\hline & Güç Kaynağ 1 - 24 VDC & & \\
\hline & $\begin{array}{l}\text { Endüstriyel PC, "İşlemci; Pentium Çift Çekirdekli } \\
\text { G3420 (2C / 2T, 3,2 GHz, } 3 \text { MB Önbellek) } \\
\text { Sürücü (SATA): 1x 500 GB HDD, Ana Bellek: } 2 \\
\text { GB DDR3 SDRAM (1x } 2 \text { GB) }\end{array}$ & & \\
\hline & Ethernet (Cat6) kablosu - 100 metre & & \\
\hline \multirow{3}{*}{ 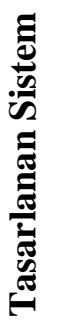 } & Raspberry Pi 3 Model B+ & \multirow{3}{*}{$\begin{array}{l}7,05 \$ \text { / } \\
\text { izleme } \\
\text { noktas1 }\end{array}$} & \multirow{3}{*}{$\begin{array}{c}\text { www.raspberrypi.org } \\
\text { [17], thingspeak.com } \\
\text { [18] }\end{array}$} \\
\hline & Güç Kaynağ 1 - 5 VDC & & \\
\hline & ThingSpeak IoT Standart Lisans - (Y1llık) & & \\
\hline
\end{tabular}

\section{IV.SONUC}

Gerçekleştirilen çalışmada uzun süreli RMS değişimlerinden kaynaklanan yüksek gerilim, düşük gerilim ve akım-gerilim dengesizliği olaylarının güç kalitesini bozucu etkileri, nesnelerin internetinden yararlanılarak endüstriyel güç kalitesi izleme seçeneklerine göre $\% 47,15$ oranında daha az yatırım maliyeti ile tespit edilerek izlenebilmiştir. İnceleme yapılan sistemde geliştirilen algoritma ile \%30,02 ile \%31,81 arasında değişen akım dengesizliği tespit edilmiş ve kayıt altına alınmıştır. Bu tip güç kalitesi problemlerinde, bozulmanın oluştuğu anlarda elde edilen belirli güç parametreleri (gerilim, akım, vb.) de kayıt altına alınmıştır. Bu sayede kayıt altına alınan güç kalitesi problemlerinin kök nedeninin bulunmasında ve güç parametrelerinin problemlerle ilişkilendirilmesinde önemli bir veri havuzu elde edilebilmektedir. Güç kalitesi problemlerinin oluştuğu anda problemin tespiti ve güç parametrelerin kayıt altında depolanması ile ilerleyen dönemlerde makine öğrenmesi ve yapay zeka uygulamaları sayesinde problemlerin tespiti daha hızlı ve ekonomik olabilecektir. Endüstride ve binalarda veriye dayalı iyileştirme çalışmalarının tespit edilmesi ve hayata geçirilmesi sistem verimliliklerinin artışına, buna bağlı olarak maliyet optimizasyonu sağlanmasına doğrudan destek olacaktır. Aynı zamanda nesnelerin interneti ve bulut teknolojilerinin gelişimi ile bu tip uygulamaların artması, büyük veri analizine imkân sağlayacak böylece endüstride ve binalarda uzun vadeli yatırımların daha doğru yapılmasına olanak sağlayacaktır.

\section{KAYNAKLAR}

[1] G. Ye, "Power quality in distribution networks: estimation and measurement of harmonic distortion and voltage dips," Ph.D. dissertation, Dept. Elect. Eng., Tech. Univ. Eindhoven, Eindhoven, 
Netherlands, 2017. [Çevrimiçi]. Erişim Adresi: https://research.tue.nl/en/publications/power-quality-indistribution-networks-estimation-and-measurement Erişim Tarihi: 10.03.2020

[2] R.C. Dugan, M. F. McGranaghan, S. Santoso, H. W. Beaty, "Introduction," in Electrical Power System Quality, 2. Bask1, New York City, New York, USA: McGraw-Hill Companies, 2002, ss. 1-10.

[3] 519-2009 IEEE Recommended Practice for Monitoring Electric Power Quality, IEEE Std 5192009, 2009.

[4] P. Kumar, "A Review of Power Quality Problems, Standards and Solutions," International Research Journal of Engineering and Technology, c. 4, s. 1, ss. 1765-1775, 2017.

[5] V. Mani, S.Sankaranarayanan, "IoT Based Smart Energy Management System," International Journal of Applied Engineering Research, c. 12, s. 16, ss. 5455-5462, 2017.

[6] D. Despa, G. F. Nama, M. A. Muhammad ve K. Anwar, "The Implementation Internet of Things(IoT) Technology in Real Time Monitoring of Electrical Quantities," in IOP Conf. Ser.: Mater. Sci. Eng. 335 012063, 2018, ss. 1-13.

[7] F. Leccese, M. Cagnetti, S. Di Pasquale, S. Giarnetti ve M. Caciotta, "A New Power Quality Instrument Based on Raspberry-Pi," Electronics, 2016. [Çevrimiçi]. Erişim Adresi: https://doi.org/10.3390/electronics5040064 Erişim Tarihi: 10.03.2020

[8] L. V. Satyanarayana, "A Survey on Challenges and Advantages in Big Data," International Journal of Computer Science and Technology, c. 6, s. 2, ss. 115-119, 2015.

[9] S. C. Vegunta, C. F. A. Watts, J. V. Milanović, S. Z. Djokic ve M. J. Higginson, "Review of GB Electricity Distribution System's Electricity Security of Supply, Reliability and Power Quality in Meeting UK Industrial Strategy Requirements," IET Generation, Transmission \& Distribution, 2019. [Çevrimiçi]. Erişim Adresi: https://doi.org/10.1049/ietgtd.2019.0052 Erişim Tarihi: 10.03.2020

[10] É. Ádámkó, G. Jakabóczki ve P. T. Szemes, "Proposal of a Secure Modbus RTU Communication with Adi Shamir's Secret Sharing Method," International Journal of Electronics and Telecommunications, c. 64, s. 2, ss. 107-114, 2018.

[11] H. Arghavani, M. Peyravi, "Unbalanced current-based tariff," in 24th International Conference \& Exhibition on Electricity Distribution (CIRED), 2017, ss. 883-887.

[12] The PostgreSQL Global Development Group. PostgreSQL 10.11 Documentation. (2019). [Çevrimiçi]. Erişim Adresi: https://www.postgresql.org/files/documentation/pdf/10/postgresql-10A4.pdf. Erişim Tarihi: 10.03.2020

[13] M. Lavanya, P. Muthukannan, Y.S.S. Bhargav, V. Suresh, "IoT Based Automated Temperature and Humidity Monitoring and Control," Journal of Chemical and Pharmaceutical Sciences, ISSN: 0974-2115.

[14] S. Suresh, H.N.S. Anusha, T. Rajath, P. Soundarya and V. Prathyusha, "Automatic Lighting and Control System for Classroom," Proceedings of 2016 IEEE International conference on ICT in Business, Industry and Government, Indore, Madhyapradesh, ss. 1-6, 2016.

[15] Vinay sagar K ,Kusuma S, " Home Automation Using Internet of Things," International Research Journal of Engineering and Technology (IRJET), c. 02, s. 03, 2015.

[16] Siemens San. ve Tic A.Ş. Siemens Fiyat Listesi. (2020). [Çevrimiçi]. Erişim Adresi: https://assets.new.siemens.com/siemens/assets/api/uuid:78ef4f0a-36b8-4d53-9dc1- 
36115b7036d/Endustriyel-Otomasyon-ve-Surucu-Teknolojileri-Fiyat-Listesi-20-07-2020.pdf Erişim Tarihi:16.09.2020

[17] Raspberry Pi Foundation UK. Products. (2020) [Çevrimiçi]. Erişim adresi: https://www.raspberrypi.org/products/ Erişim Tarihi: 16.09.2020

[18] The MathWorks, Inc, ThingSpeak. How to Buy (2020) [Çevrimiçi]. Erişim adresi: https://thingspeak.com/prices/thingspeak_standard Erişim Tarihi: 16.09.2020 